\title{
Preparation of monodispersed and cytotoxic silver nanoparticles using Launaea taraxacifolia leaf extract
}

\author{
Enobong R. Essien ${ }^{1}\left(\mathbb{D} \cdot\right.$ Violette N. Atasie ${ }^{1} \cdot$ Esther U. Udobang ${ }^{1} \cdot$ Goddey Umanu $^{2}$
}

Received: 26 June 2019 / Accepted: 28 August 2019 / Published online: 5 September 2019

(c) The Author(s) 2019

\begin{abstract}
The current work investigated the green and low-cost preparation of silver nanoparticles (AgNPs) using the aqueous extract from Launaea taraxacifolia leaf and studied its antimicrobial effects. The leaf extract was analysed in a gas chromatogrammass spectrometer to assess the phytochemicals present. UV-Vis spectrophotometer was used to monitor the formation of AgNPs, the morphological assessment was performed by a scanning electron microscope, energy dispersive X-ray analysis was used to determine the elemental composition, the particle size and shape were studied using transmission electron microscopy, and the vibrational modes of bonds in the AgNPs were assessed by Fourier transformed infrared spectroscopy. The AgNPs produced were spherical and in a size range of 9-15.5 nm, monodispersed with a large surface area. The minimum inhibitory concentration (MIC) and minimum bactericidal concentration (MBC) of the AgNPs against Pseudomonas aeruginosa and Proteus mirabilis were very low. Against $P$. aeruginosa, the MIC was $0.10 \mathrm{mg} / \mathrm{mL}$ and the MBC was $0.15 \mathrm{mg} / \mathrm{mL}$, while the MIC and MBC against P. mirabilis were 0.05 and $0.25 \mathrm{mg} / \mathrm{mL}$, respectively. Therefore, the AgNPs prepared using $L$. taraxacifolia leaf extract showed high antibacterial activities and could be a candidate antimicrobial agent for biomedical applications.
\end{abstract}

Enobong R. Essien

reggiessien@gmail.com

1 Department of Chemical and Food Sciences, Bells

University of Technology, P.M.B 1015, Ota, Ogun State,

Nigeria

2 Department of Biological Sciences, Bells University

of Technology, P.M.B 1015, Ota, Ogun State, Nigeria 


\section{Graphic Abstract}
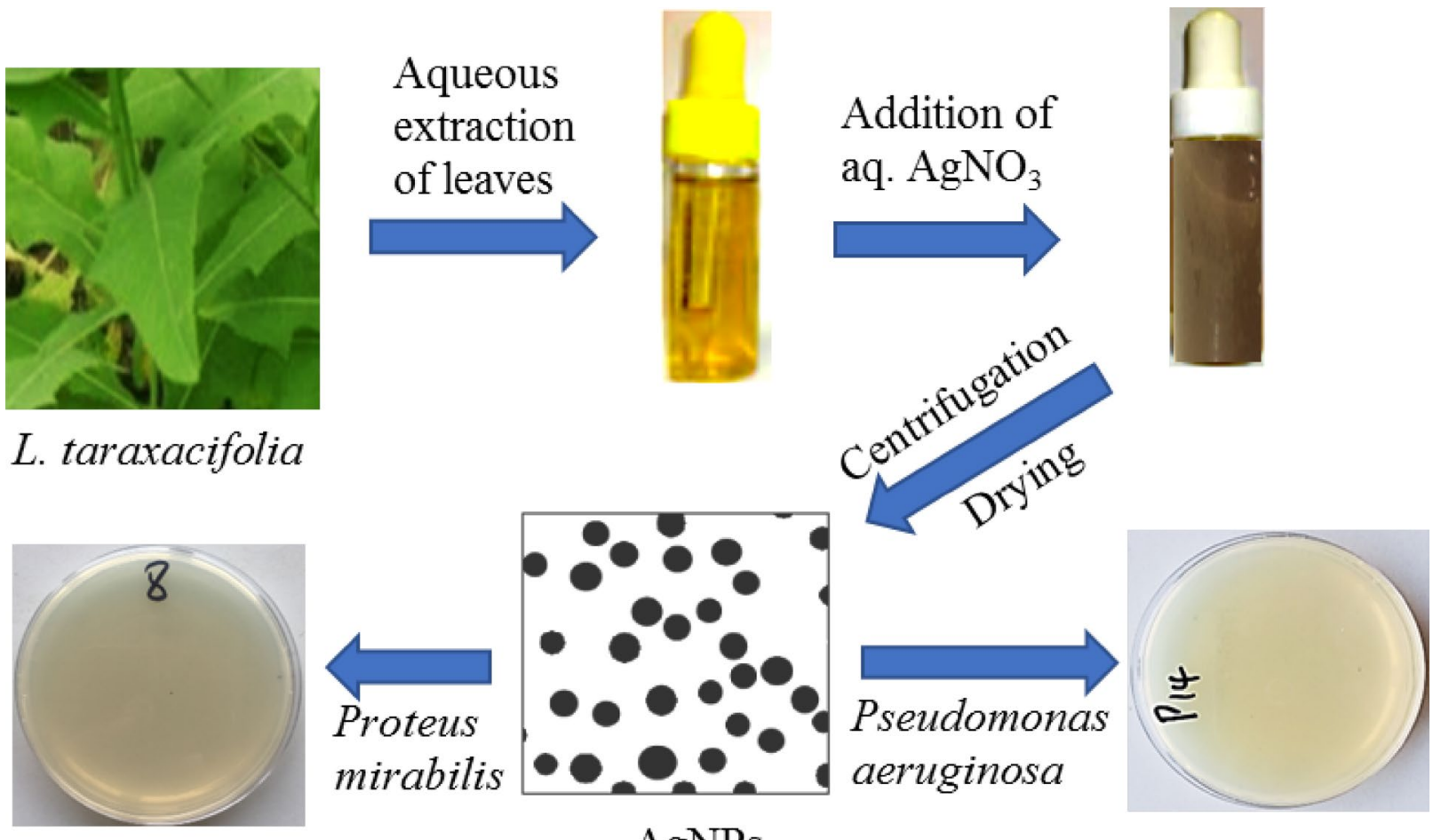

AgNPs

Keywords Launaea taraxacifolia $\cdot$ Silver nanoparticles $\cdot$ Antimicrobial agent $\cdot$ Phytochemicals $\cdot$ Monodisperse

\section{Introduction}

Nanotechnology has great potential in the field of materials science for producing materials of various types at nanoscale level. Nanomaterials have minimum dimension in the nonmetre scale $(1-100 \mathrm{~nm})$, which is in the size dimension of microorganisms like viruses or bacteria. In this dimension, nanomaterials can generate therapeutic activities and several other unique properties [1] compared with their corresponding bulk materials. This is because their physicochemical properties, like surface charge, surface area, size, and shape greatly influence their properties. The 'green approach' method of synthesizing silver nanoparticles (AgNPs) has become very attractive in chemical synthesis, thanks to the sustained worldwide awareness campaigns and concerns regarding the dangers associated with environmental pollution [2]. At the nanometre scale, silver has applications in various fields, including medicine, biosensors, and analysis. AgNPs have long been credited with strong inhibitory effects against bacteria and fungi found in medical and industrial processes [3, 4]. Thus, AgNPs have been applied in topical ointments to stop burns and open wounds from being infected [5]. Besides, biologically synthesized AgNPs are highly toxic to several multi-drug resistant human pathogens, and in monodisperse morphology, they are more effective in drug delivery, resonance imaging, and medical diagnostics [6].

There are many chemical techniques of synthesizing AgNPs, some involve reducing silver ions chemically in aqueous solutions, which could employ stabilizing agents. Others are decomposing silver ion thermally in organic solvents, chemical reduction and carrying out photoreduction in reverse micelles $[7,8]$, and using radiation chemical reduction method [9]. However, most of these techniques are complex and involve the use of very expensive equipment [10]. Furthermore, these processes may release harmful gases into the atmosphere and the chemicals used may be hazardous and dangerous to health and pollute the environment as well [10].

The plant extract alternative pathway for synthesizing AgNPs, apart from its eco-friendliness, has the advantages of being facile and cost effective [11, 12]. Additionally, in plant-mediated synthesis, the phytochemicals inherent in the plants, after playing a reducing role, also act as capping agents towards forming the nanoparticles. Based on this, the AgNPs obtained from this technique are safe for human medical use $[12,13]$. 
Launaea taraxacifolia is a leafy vegetable found mainly in the tropical regions and has the common name 'Dandelion'. It owes its origin to the family Asteraceae (Compositae) and is commonly found in several African countries including Ghana, Senegal, Benin, and Nigeria. L. taraxacifolia has also been shown to play a crucial role in curbing non-communicable diseases in man. There is a report that the milky fluid which exudes from the plant possesses therapeutic effect against conjunctivitis, and at a specific dosage, the leaves have been shown to provide protection against gentamicin-induced kidney damage in rats [14].

Launaea taraxacifolia is probably one plant that is most grossly understudied among leafy vegetables [15], ranking among "the ten most neglected and underutilized plants" $[16,17]$, yet it is very easily found as weed and roadside grass. It is against this backdrop that the current work is designed to synthesize AgNPs from L. taraxacifolia leaf and study their inhibitory effects against two strains of bacteria. Based on our investigation, there is currently no report in literature on the preparation of silver AgNPs from L. taraxacifolia.

\section{Experimental}

\section{Materials}

The L. taraxacifolia leaves used for this research work were obtained from the premises of Bells University of Technology, Ota, Ogun State, southwest Nigeria and identified at the Herbarium section of Botany Department, University of Lagos, Nigeria. $\mathrm{AgNO}_{3}$ was purchased from Sigma-Aldrich.

\section{Preparation of $L$. taraxacifolia leaf aqueous extract}

The $L$. taraxacifolia leaves were first washed with tap water and further rinsed with distilled water to remove dust and particulate impurities. Thereafter, they were allowed to dry at ambient condition and at $70{ }^{\circ} \mathrm{C}$ in an oven before milling into a fine powder, and then stored in an airtight container for further use. Then, the powder $(4.0 \mathrm{~g})$ was added to distilled water $(100 \mathrm{~mL})$, sealed and heated to $65^{\circ} \mathrm{C}$ for $15 \mathrm{~min}$ in a thermostatic water bath. After allowing to cool to room temperature, the mixture was filtered to obtain the $L$. taraxacifolia aqueous leaves extract. The obtained extract was stored at a temperature range $5-10{ }^{\circ} \mathrm{C}$ in a refrigerator for subsequent experiments.

\section{Synthesis of AgNPs}

The synthesis was performed by modifying a previous method by Krishnamoorthy and Jayalakshmi [18]. Briefly, $1 \mathrm{~mL}$ of the L. taraxacifolia aqueous leaf extract was added to $9 \mathrm{~mL}$ of $10 \mathrm{mM}$ solution of $\mathrm{AgNO}_{3}$. The reaction was performed in a dark room at room temperature and left overnight to minimize photoactivation of the $\mathrm{AgNO}_{3}$. After the desired reaction period, the solution containing the AgNPs was centrifuged at $15,000 \mathrm{rpm}$ for $15 \mathrm{~min}$ to separate them from the reaction solution. The particles formed were washed in deionized water to remove any residual organic compounds still present in the AgNPs. This washing procedure was repeated thrice to increase the purity of the AgNPs, and, thereafter, the wet particles were dried at $60{ }^{\circ} \mathrm{C}$ in an oven. Finally, the particles were stirred in absolute ethanol to reduce aggregation and then dried at $60{ }^{\circ} \mathrm{C}$ for $30 \mathrm{~min}$ in an oven to expel the solvent.

\section{Characterization techniques}

A gas chromatograph-mass spectrometer (GC-MS) (Shimadzu, QP2010SE) performing at a 1:1 injection ratio was used to determine the phytochemicals present in the ethanolic solution of the L.taraxacifolia leaf extract. The phytochemicals were identified using a software having a database incorporated into the GC-MS machine.

UV-Vis spectral details were recorded in a UV-visible absorption spectrophotometer (Uniscope SM 7504) in the wavelength between $300 \mathrm{~nm}$ and $700 \mathrm{~nm}$ to monitor the formation of AgNPs in the reaction medium between $L$. Taraxacifolia leaf extract and $\mathrm{AgNO}_{3}$. The UV-visible spectrum of the L. Taraxacifolia leaf extract was also obtained at a similar wavelength range.

A morphological evaluation to determine the microstructure, particle distribution and elemental composition of the AgNPs was performed in a scanning electron microscope (SEM) having an energy dispersive X-ray analysis (EDX) unit (SEM: JEOL JSM 7660F). The sample was analysed using an accelerating voltage of $15 \mathrm{kV}$.

The particle size and structure of the AgNPs were assessed by transmission electron microscopy (TEM) (TEM: JEM-ARM200F-G) operating at $200 \mathrm{kV}$ accelerating voltage. The average particle size and distribution were determined from the TEM micrograph using a software-ImageJ.

The type of bonds present in the L. taraxacifolia aqueous leaf extract and AgNPs was assessed using Fourier transform infrared (FTIR) spectroscopy (FTIR: Nicolet iS10) in the wavenumber range of $350-4000 \mathrm{~cm}^{-1}$.

\section{Antimicrobial analysis}

Broth dilution method as described by Krishnan et al., 2015 [19] was employed in the preparation of the AgNPs samples to determine the minimum inhibitory concentration (MIC) and minimum bactericidal concentration (MBC). The Luria-Bertani (LB) broth used for the experimental analysis 
was prepared based on the manufacturer's instructions using deionized water as the broth diluent.

A stock solution containing $10 \mathrm{mg} / \mathrm{mL}$ of the AgNPs was used for the determination of the MICs. It was prepared by sonicating the AgNPs in deionized water at $40^{\circ} \mathrm{C}$ in an ultrasonic cleaner (CLEAN-120HD) for $5 \mathrm{~h}$ to achieve a homogeneous, cloudy solution. The antibacterial potencies of the AgNPs against clinically isolated Gram-negative Pseudomonas aeruginosa and Proteus mirabilis were determined by inoculating varying amounts of the AgNPs (prepared from the stock solution, Table 1) with suspensions of the test microorganisms. Bacterial suspensions of the test strains were prepared using a $0.5 \mathrm{McF}$ arland turbidity standard. $50 \mu \mathrm{L}$ of the prepared suspension was inoculated into each of the serially diluted tubes containing the AgNPs at concentrations of $4-0.01 \mathrm{mg} / \mathrm{mL}$ (Table 1). Negative and positive control tubes were also prepared to check the sterility of the procedure and the bacterial activity, respectively. The negative control tube contained only sterile broth, while

Table 1 Working concentrations of the AgNPs for MIC determination using Pseudomonas aeruginosa and Proteus mirabilis as test microorganisms

\begin{tabular}{lllll}
\hline \multicolumn{2}{l}{ Pseudomonas aeruginosa } & & \multicolumn{2}{l}{ Proteus mirabilis } \\
\cline { 1 - 2 } Dilution code & $\begin{array}{c}\text { AgNPs concen- } \\
\text { tration (mg/mL) }\end{array}$ & Dilution code & $\begin{array}{c}\text { AgNPs concen- } \\
\text { tration (mg/mL) }\end{array}$ \\
\hline P7 & 4 & N7 & 0.50 \\
P8 & 3 & N8 & 0.25 \\
P9 & 2 & N9 & 0.20 \\
P10 & 1 & N10 & 0.15 \\
P11 & 0.5 & N11 & 0.10 \\
P12 & 0.25 & N12 & 0.05 \\
P13 & 0.20 & N13 & 0.04 \\
P14 & 0.15 & N14 & 0.03 \\
P15 & 0.10 & N15 & 0.02 \\
P16 & 0.05 & N16 & 0.01 \\
\hline
\end{tabular}

the positive control tube contained the broth and bacterial inoculum, but no antimicrobial agent. After $24 \mathrm{~h}$ of incubation at $37{ }^{\circ} \mathrm{C}$, the MIC values were obtained by checking for visual turbidity in the tubes. The lowest concentrations of the AgNPs that visually inhibited the growth of the test microorganisms were taken as the MICs.

To determine the minimum bactericidal concentration (MBC), $50 \mu \mathrm{L}$ aliquots from all the tubes which showed no visible bacterial growth were seeded in LB agar plates devoid of the antimicrobial agent (AgNPs). The plates were labelled according to the dilution tubes from where their inoculums were obtained and then incubated for $24 \mathrm{~h}$ at $37{ }^{\circ} \mathrm{C}$. Thereafter, the agar plates were observed for the presence or absence of bacterial growth. The plate representing the lowest concentration of the AgNPs which did not exhibit any bacterial growth or colony was taken as the MBC. MBC is defined as the lowest concentration of antimicrobial agent that kills $99.9 \%$ of the initial test bacterial population [19].

\section{Results and discussion}

\section{UV-Vis spectrophotometry}

During the biosynthesis reaction, colour change occurred as the solution changed colour from buff to brown as a result surface plasmon resonance (SPR) phenomenon caused by the formation of the AgNPs [20]. The solution was analysed immediately after the colour change was observed, which indicated a reduction of the silver ion $\left(\mathrm{Ag}^{+}\right)$to pure silver $\left(\mathrm{Ag}^{0}\right)$. The UV-Vis absorption spectrum of the AgNPs solution showed a strong and sharp absorption band centred at $440 \mathrm{~nm}$ (Fig. 1a) which corresponds to the dipole resonance of $\mathrm{Ag}$ nanospheres and agrees with previous findings [21-23]. The absence of additional absorption bands at higher wavelengths indicates spherical shape uniformity of the nanoparticles [24]. The UV-Vis spectrum recorded and the visual observation made indicated that a bio-reduction
Fig. 1 UV-Vis spectra of a the colloidal solution containing AgNPs showing absorption at $440 \mathrm{~nm}$ and $\mathbf{b}$ aqueous extract of L. taraxacifolia leaf showing no absorption peaks
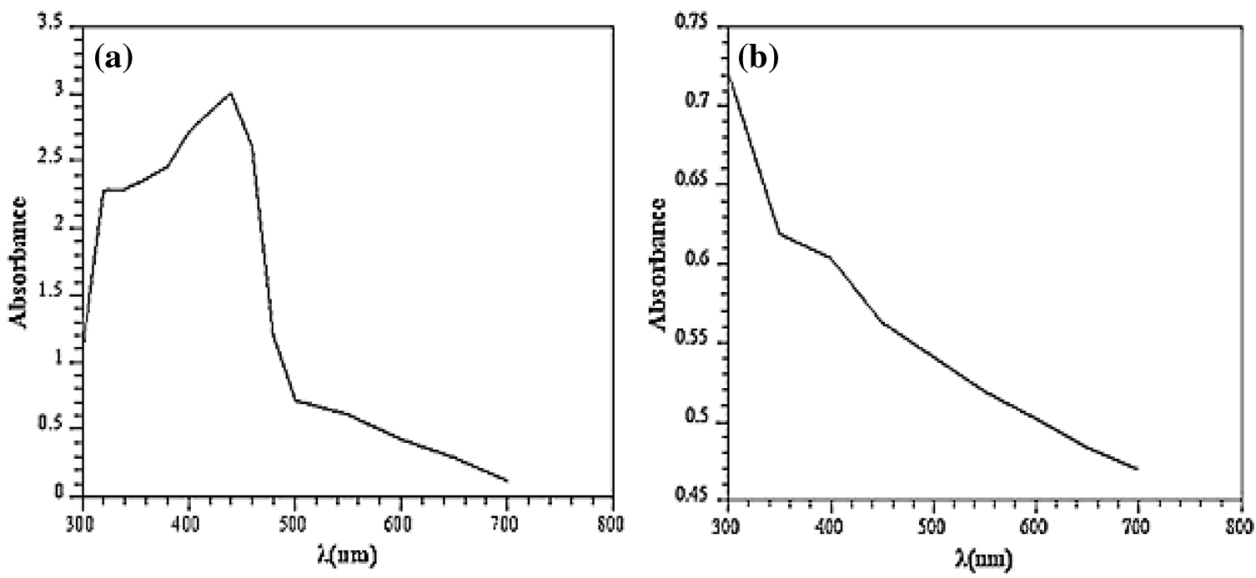
reaction occurred giving rise to the formation of AgNPs. This is in contrast to the UV-Vis spectrum of the $\mathrm{AgNO}_{3}$ (Fig. 1b) solution, which appeared as a band without an absorption peak.

\section{Phytochemicals present in the L. taraxacifolia leaf extract and probable mechanism of AgNPs formation}

The retention times and peak heights of the major metabolites identified in the L. taraxacifolia leaf extract by GC-MS are shown in the chromatogram in Fig. 2 and Table 2. The result indicated that most of the biomolecules are alcohols, amides and carbohydrates. Reports indicate that plant leaf extracts containing carbohydrate and proteins with amino functional groups serve as reductants to reduce silver ions

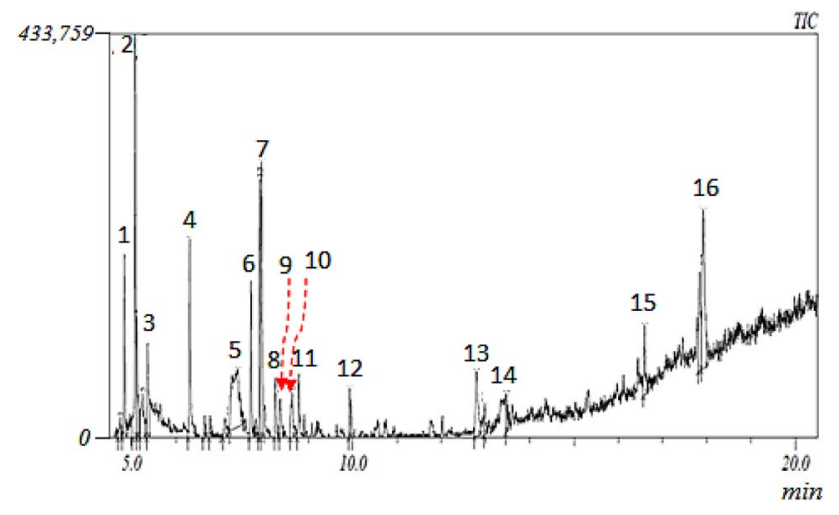

Fig. 2 Chromatogram showing peaks with different intensities of the phytochemicals present in the L. taraxacifolia leaf extract (shown in Table 2)
$\left(\mathrm{Ag}^{+}\right)$to silver nanoparticles $\left(\mathrm{Ag}^{0}\right)[25,26]$. Amides, in particular, have been shown to act as reducing and capping agents to obtain AgNPs [27, 28].

\section{Microstructure and elemental composition of the AgNPs}

The morphological features of the AgNPs are presented in Fig. 3. As observed, the microstructure shows homogeneous spherical particles that are mostly devoid of agglomeration, and consequently, presents excellent distribution and large surface area. Particle topography, including size and distribution are known to be important for nanoparticles to exhibit antimicrobial and optical properties [28-30]. The shape of the AgNPs as observed in the SEM micrograph was spherical and uniform, thus supporting the UV-Vis result.

The formation of AgNPs was further supported by the presence of Ag peak at high intensity in the EDX spectrum (Fig. 4). The carbon and oxygen atoms observed in the spectrum are from the plant phytochemicals which participated in the reducing and capping reactions to produce the AgNPs. However, the $\mathrm{K}, \mathrm{Si}$, and $\mathrm{S}$ appearing in the spectrum at very low intensity could be residual impurities from the aqueous leaf extract which were not completely removed after washing the nanoparticles following their centrifugation.

\section{Particle size dimension and distribution}

TEM evaluation reveals that the particles were spherical, monodisperse with no agglomerates (Fig. 5). This could be the result of the efficient reduction of the $\mathrm{Ag}^{+}$to $\mathrm{Ag}^{0}$ followed by growth into isolated nanoparticles. It also reflects, jointly, the capping ability of the biomolecules present and
Table 2 Major phytochemicals identified in the L. taraxacifolia leaf extract using GC-MS

\begin{tabular}{lccl}
\hline Peak no. & Retention time & Peak height & Name \\
\hline 1 & 4.837 & 196,808 & 2-Amino-1,3-propanediol \\
2 & 5.085 & 433,759 & Dihydroxydimethylsilane \\
3 & 5.357 & 101,100 & 1-Hydroxy-2-butylamine \\
4 & 6.314 & 212,582 & Methyl $N$-hydroxybenzenecarboximidoate \\
5 & 7.393 & 61,535 & Glycerol \\
6 & 7.700 & 169,379 & 2,2'-Dihydroxydipropyl ether \\
7 & 7.935 & 296,573 & 2-(2-Hydroxypropoxy)-1-propanol \\
8 & 8.249 & 63,585 & (E)-2-isopropyl-5-methylphenyl 2-methylbut-2-enoate \\
9 & 8.360 & 44,890 & 2-Pyrrolidinone \\
10 & 8.630 & 161,500 & $1,4: 3,6-$ Dianhydro-alpha-D-glucopyranose \\
11 & 8.782 & 67,902 & Maltol \\
12 & 9.927 & 53,080 & 1,4:3,6-Dianhydro-alpha-D-glucopyranose \\
13 & 12.791 & 69,388 & 1,6 -Anhydro-beta-D-glucopyranose \\
14 & 13.460 & 41,182 & dl-.Alpha-tocopherol \\
15 & 16.565 & 75,131 & Ethyl 14-methyl-hexadecanoate \\
16 & 17.924 & 170,855 & Alpha-tocopherol \\
\hline
\end{tabular}




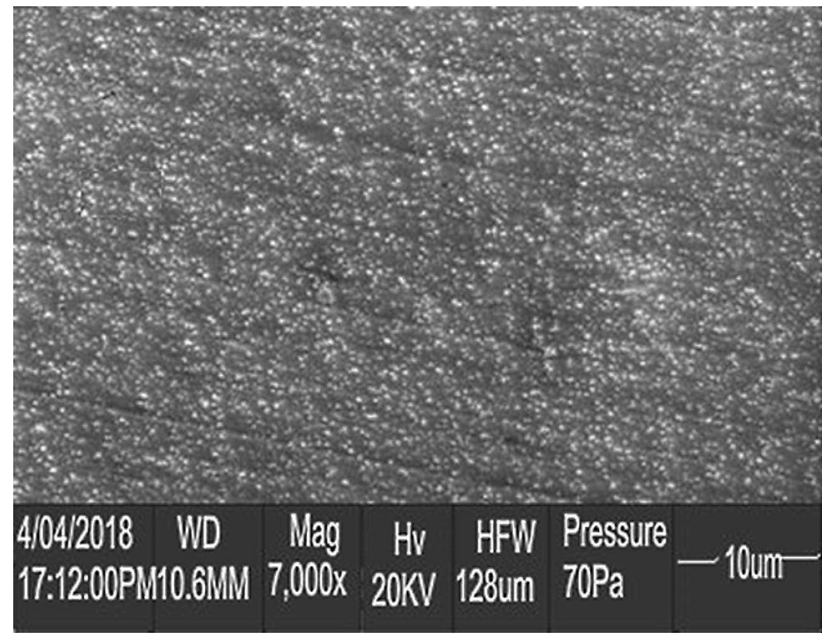

Fig. 3 SEM micrograph of the AgNPs showing well-distributed particles

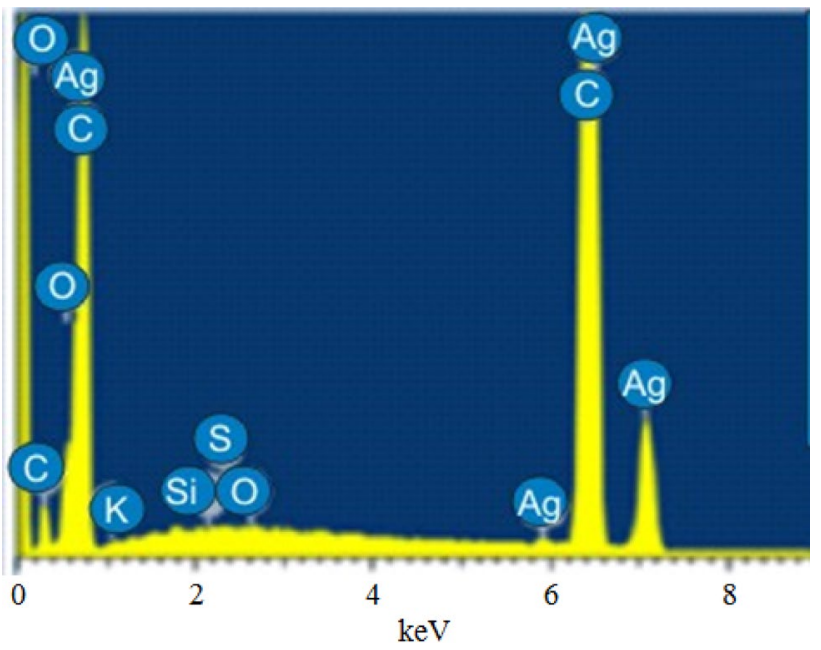

Fig. 4 EDX spectrum of the AgNPs showing the presence of silver at high concentration

the effect of the ethanol medium to prevent agglomeration, and thus verifies the result obtained by the absorption spectrophotometry. The AgNPs vary in sizes from 9 to $15.5 \mathrm{~nm}$ as shown in the histogram presented in Fig. 6, but with an average size of $12 \mathrm{~nm}$. This result is quite remarkable because synthesizing monodisperse nanoparticles with uniform size, shape, and composition is a challenging endeavour [31].

\section{Bond characteristics of the AgNPs}

Figure 7 depicts the FTIR spectra of the AgNPs and the aqueous leaf extract of L. taraxacifolia. The spectrum of the AgNPs (Fig. 7a) reveals the presence of vibrational modes at 3780, 3459, 1636, 1441 and $1143 \mathrm{~cm}^{-1}$. The

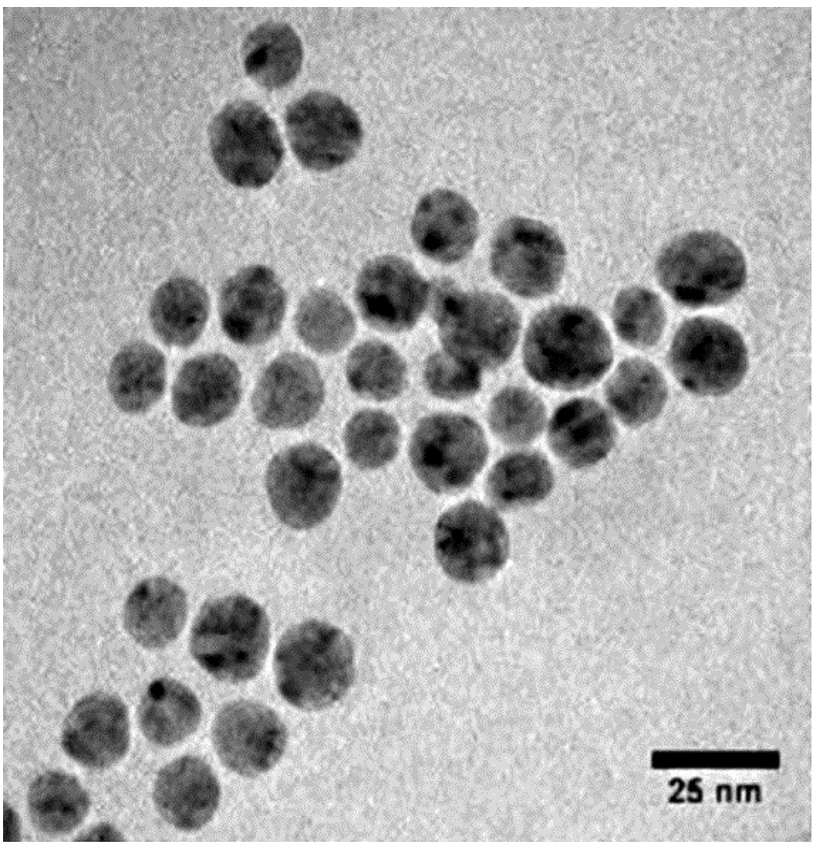

Fig. 5 TEM image of the AgNPs showing monodisperse particles

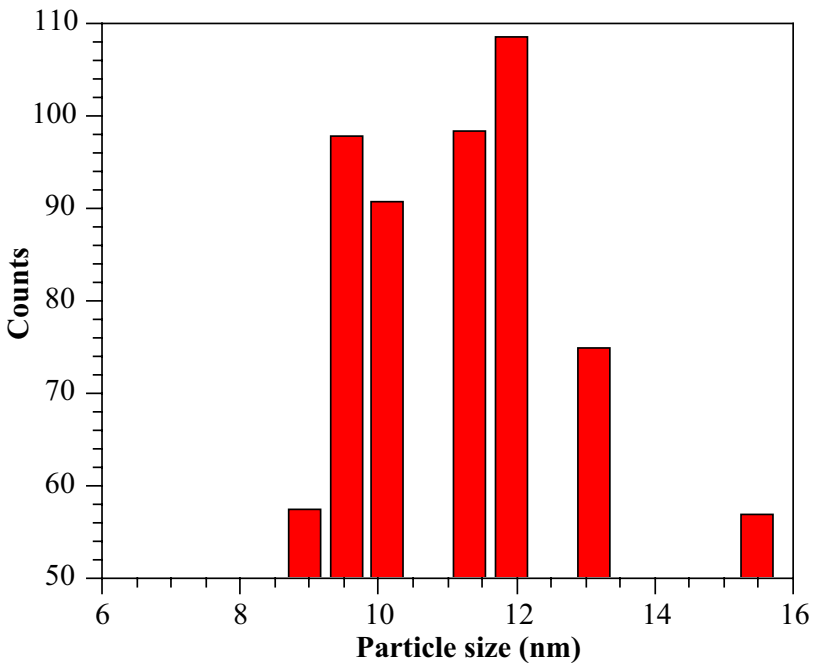

Fig. 6 Particle size distribution of the AgNPs showing that the particle size was distributed between 9 and $15.5 \mathrm{~nm}$ with the average at $12 \mathrm{~nm}$

small peak appearing as a shoulder around $3780 \mathrm{~cm}^{-1}$ is considered to be $\mathrm{N}-\mathrm{H}$ stretching vibration resulting from the presence NH group in the sample [32]. The broad band centred at $3459 \mathrm{~cm}^{-1}$ is attributed to $\mathrm{O}-\mathrm{H}$ stretching vibration of water molecules or $\mathrm{N}-\mathrm{H}$ [32], while the sharp peak near $1636 \mathrm{~cm}^{-1}$ is associated with $\mathrm{C}=\mathrm{O}$ stretching vibration of an amide [27], which is further confirmed by the $\mathrm{C}-\mathrm{O}$ deformation mode at $1143 \mathrm{~cm}^{-1}$. The small peak around $1441 \mathrm{~cm}^{-1}$ signifies the presence of $\mathrm{C}-\mathrm{H}$ bond in 


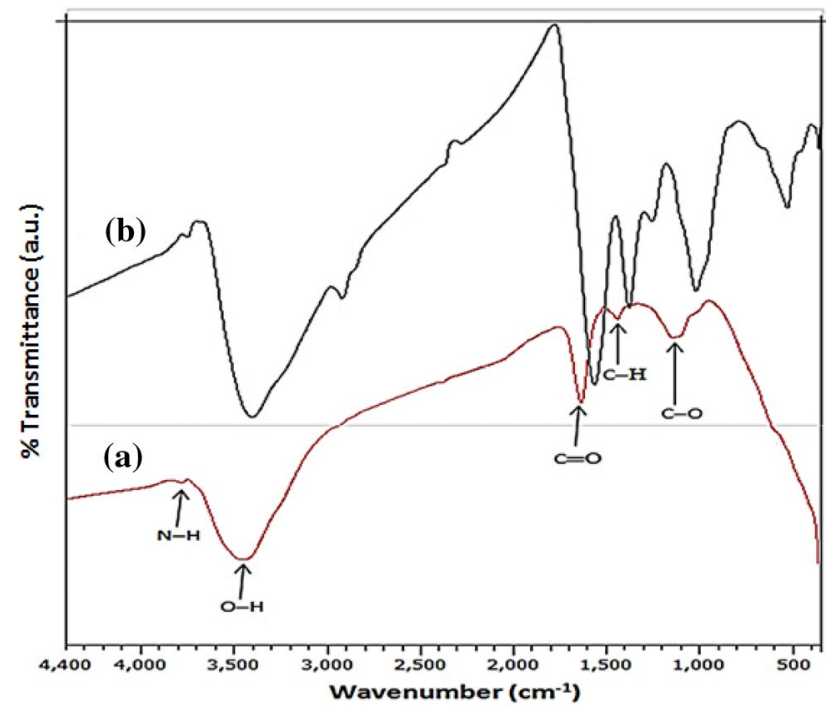

Fig. 7 FTIR spectra of a the AgNPs and $\mathbf{b}$ the L. taraxacifolia aqueous leaf extract

$\mathrm{CH}_{2}$ [33]. The result of the FTIR confirms that the phytochemicals present in the leaf extract were involved in the reduction and stabilization reaction for the formation of the AgNPs. Several peaks are observed between 3780 and $530 \mathrm{~cm}^{-1}$ in the FTIR spectrum of the aqueous leaf extract (Fig. 7b). These peaks are vibrations of the bonds of different phytochemicals earlier identified by GC-MS and shown previously in Table 2 .

\section{Antibacterial activity of the AgNPs}

The dilution tubes of the AgNPs solutions which were used to determine the MIC which inhibited the growth of the clinically isolated $P$. aeruginosa and $P$. mirabilis are presented in Figs. 8 and 9, respectively. In the antimicrobial test against $P$. aeruginosa (Fig. 8), the negative control (test tube TX) containing only sterilized LB broth showed no turbidity, and thus verifies the sterility of the experimental procedure; and the positive control (test tube TY) containing sterilized LB broth and the test organism only validates the results of the experiment by showing heavy turbidity as a result of bacterial growth. Turbidity was also visible in tube P16 at $0.05 \mathrm{mg} / \mathrm{ml}$ concentration of the AgNPs, while MIC for the AgNPs was recorded at $0.10 \mathrm{mg} / \mathrm{mL}$ (P15), the lowest concentration with no visible turbidity.

For the antibacterial action against $P$. mirabilis (Fig. 9), turbidity was observed up to the value $0.04 \mathrm{mg} / \mathrm{mL}$ of AgNPs concentration (test tube N13), while MIC was recorded at a concentration of $0.05 \mathrm{mg} / \mathrm{mL}$ (test tube $\mathrm{N} 12$ ).

The minimum bactericidal concentration $(\mathrm{MBC})$ was determined by seeding LB agar plates devoid of antimicrobial agent (AgNPs) with aliquots $50 \mu \mathrm{l}$ from all tubes which showed no visible bacterial growth. After incubation, the MBC was obtained by observing the plates for the presence or absence of bacterial growth (Figs. 10,11). The plates inoculated with inoculum from the lowest AgNPs concentration tube that showed no growth (no visible colony) is the MBC. The plate inoculated with inoculum from tube
Fig. 8 Broth dilution tubes for the determination of MIC of AgNPs against clinically isolated Pseudomonas aeruginosa showing MIC at $0.10 \mathrm{mg} / \mathrm{ml}$ in $\mathrm{P} 15$
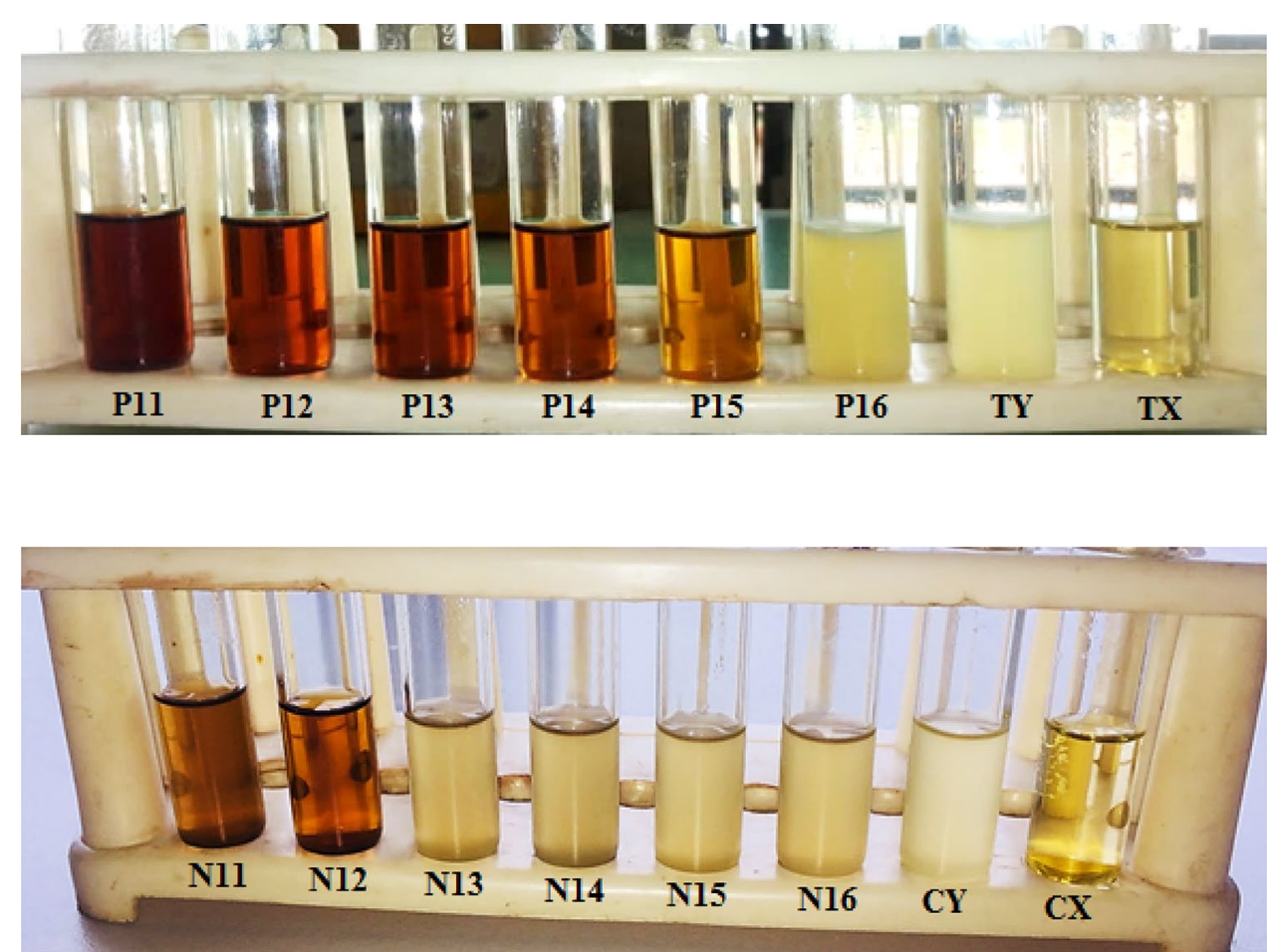

Fig. 9 Broth dilution tubes for the determination of MIC of AgNPs against clinically isolated Proteus mirabilis showing $\mathrm{MIC}$ at $0.05 \mathrm{mg} / \mathrm{mL}$ in $\mathrm{N} 12$ 


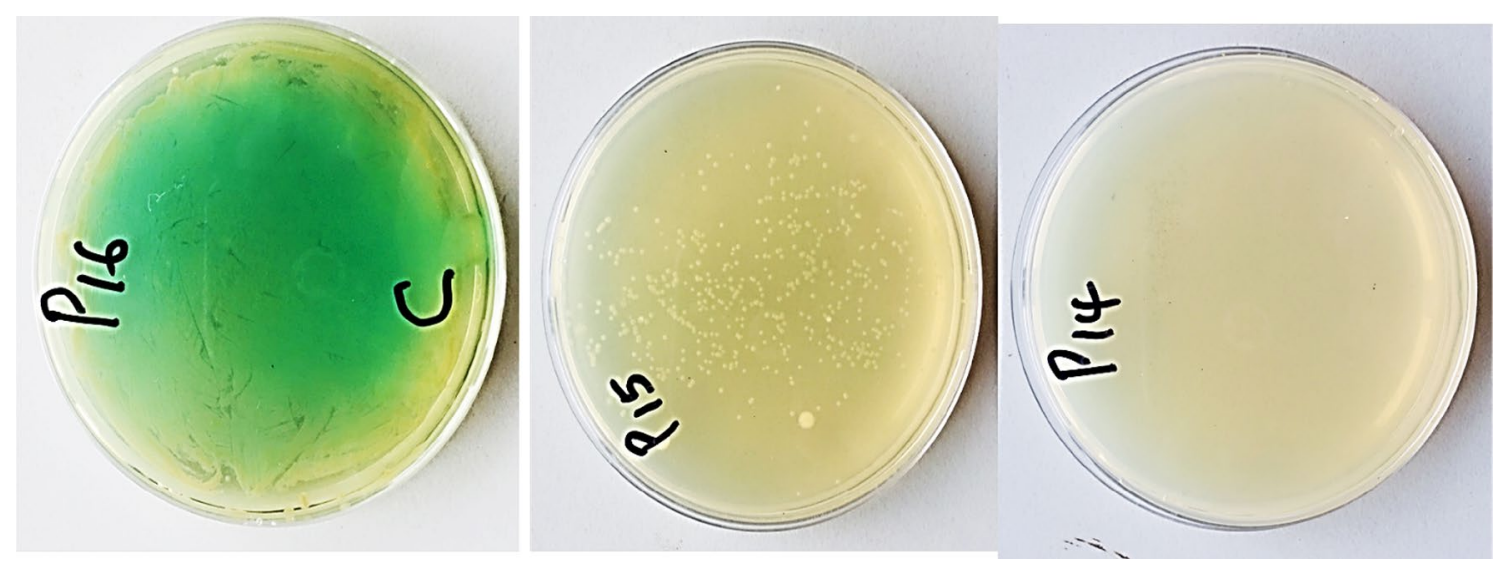

Fig. 10 Agar plates showing antibacterial potency of AgNPs against Pseudomonas aeruginosa. MBC was recorded at $0.15 \mathrm{mg} / \mathrm{mL}$ in P14

Fig. 11 Agar plates showing antibacterial potency of AgNPs against Proteus mirabilis. MBC was detected at $0.25 \mathrm{mg} / \mathrm{mL}$ (N8)
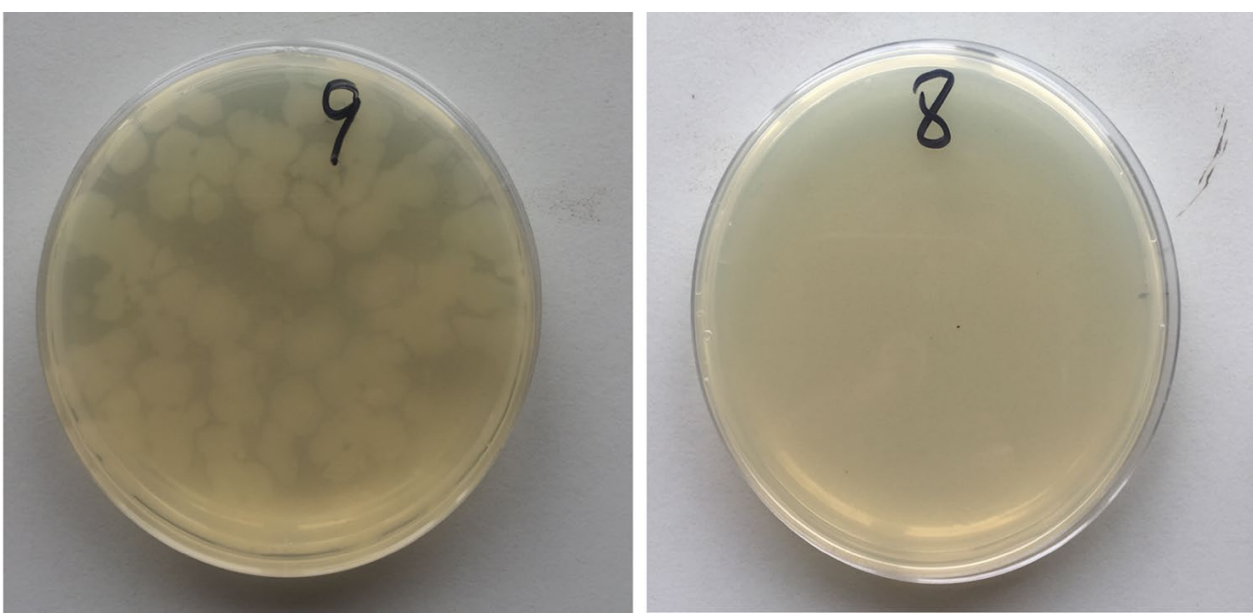

P16 (the highest concentration which showed visible turbidity) was used as control to verify that the turbidity was indeed the result of bacterial growth of the test $P$. aeruginosa (Fig. 10). After overnight incubation, heavy growth, shown by green coloration on the agar plate was observed (Fig. 10), which resulted from the chromogenic nature of the test bacteria. It was observed that in plate P15 $(0.10 \mathrm{mg} / \mathrm{mL})$, the bacterial cells had resumed growth, while P14 containing $0.15 \mathrm{mg} / \mathrm{mL}$ concentration of AgNPs showed no bacterial growth and was hence recorded as the MBC of the AgNPs against the $P$. aeruginosa strain.

Proteus mirabilis agar plates are shown in Fig. 11. MBC for this strain of bacteria was recorded at $0.25 \mathrm{mg} / \mathrm{mL}$ (plate N8). There was a resumption of bacterial proliferation in agar plate $\mathrm{N} 12(0.05 \mathrm{mg} / \mathrm{mL}$ concentration), indicating that the bacterial activity was only inhibited at that concentration.

From the MIC and MBC determination results obtained from this study, the synthesized AgNPs showed cytotoxicity at unusually low concentrations, which is in contrast with previous studies on AgNPs synthesized via plant-mediated routes
$[19,34,35]$ that lay between 5 and $15 \mathrm{mg} / \mathrm{mL}$. However, the data agree with other reports that obtained MIC and MBC from plant-derived AgNPs between 0.05 and $0.1 \mathrm{mg} / \mathrm{mL}$ [36, 37].

The high degree of potency could be due to the excellent surface topography containing homogeneous, spherical, monodisperse particles of average size $12 \mathrm{~nm}$. Several in vitro studies [29-40] have provided evidence that particle size and shape uniformity are important in cytotoxicity, because they influence cellular membrane deformability, biodistribution and the kinetics of absorbability [30]. Furthermore, the monodisperse nature of the AgNPs promoted toxicity due to better penetration and destruction of the cell walls of the bacteria [41, 42]. 


\section{Conclusions}

Silver nanoparticles have been synthesized successfully using the phytochemicals in aqueous leaf extract of $L$. taraxacifolia as the reducing agent. The AgNPs obtained were spherical, monodisperse and in the size range 9-15.5 $\mathrm{nm}$. These properties were attributed to the inherent phytochemicals present in the leaf of the $L$. taraxacifolia plant which, effectively reduced the $\mathrm{Ag}^{+}$in the solution to $\mathrm{Ag}^{0}$ and subsequently stabilized the formed AgNPs by preventing oxidation. FTIR analysis further supported the involvement of these metabolites in the capping reaction with the nanoparticles. Antimicrobial investigation on two strains of bacteria, $P$. aeruginosa and $P$. mirabilis, revealed high cytotoxicity kinetics for the AgNPs. For $P$. aeruginosa, MICs were detected at 0.10 and $\mathrm{MBC}$ at $0.15 \mathrm{mg} / \mathrm{mL}$, while for P. mirabilis, the MIC and MBC were detected at 0.05 and $0.25 \mathrm{mg} / \mathrm{mL}$, respectively. This indicated high AgNPs penetration across the bacteria cell walls, even at low concentration, attributable to the desirable particle topography.

Interestingly, the synthesis of the monodisperse AgNPs was facile and could be performed without requiring complex equipment and reagents compared to those in previous studies. GC-MS investigation shows that $L$. taraxacifolia leaf, which is yet to be explored in the ever-evolving field of plant-based synthesis of nanoparticles, contains important metabolites that could be useful as reducing and capping agents for preparing highly cytotoxic AgNPs. Additionally, L. taraxacifolia is regarded as a weed, its consumption as food vegetable is not documented, hence being widely available, could be very useful for large-scale plant-mediated synthesis of AgNPs.

The future perspectives for L. taraxacifolia in this study would be its use for the green and economic synthesis of other metal and metal oxide nanoparticles.

Acknowledgements We are grateful to Mr. Ata Samuel Akhihiero, Geology Department of the University of Ibadan, Nigeria for helping in the SEM, EDX, TEM and FTIR analysis of the samples. We also thank the Department of Microbiology, Bells University of Technology, Ota for providing access to their laboratory to conduct the antimicrobial studies.

Open Access This article is distributed under the terms of the Creative Commons Attribution 4.0 International License (http://creativecommons.org/licenses/by/4.0/), which permits unrestricted use, distribution, and reproduction in any medium, provided you give appropriate credit to the original author(s) and the source, provide a link to the Creative Commons license, and indicate if changes were made.

\section{References}

1. Iqbal, J., Abbasi, B.A., Ahmad, R., Mahmood, T., Ali, B., Khalil, A.T., Kanwal, S., Shah, S.A., Alam, M.M., Badshah, H., Munir, A.: Nanomedicines for developing cancer nanotherapeutics: from benchtop to bedside and beyond. Appl. Microbiol. Biotechnol. 102, 9449-19470 (2018)

2. Thuesombat, P.S., Hannongbua, S., Akasit, S., Chadchawan, S.: Effect of silver nanoparticles on rice (Oryza sativa L. cv. KDML $105)$ seed germination and seedling growth. Ecotox. Environ. Saf. 104C, 302-309 (2014)

3. Morones, J.R., Elechiguerra, J.L., Camacho, A., Holt, K., Kouri, J.B., Ramírez, J.T., Yacaman, M.J.: The bactericidal effect of silver nanoparticles. Nanotechnology 16, 2346-2353 (2005)

4. Lok, C., Ho, C., Chen, R., He, Q., Yu, W., Sun, H., Tam, P.K., Chiu, J.F., Che, C.M.: Silver nanoparticles: partial oxidation and antibacterial activities. J. Biol. Inorg. Chem. 12, 527-534 (2007)

5. Ip, M., Lui, S.L., Poon, V.K.M., Lung, I., Burd, A.: Antimicrobial activities of silver dressings: an in vitro comparison. J. Med. Microbiol. 55, 59-63 (2006)

6. Xie, J., Peng, S., Brower, N., Pourmand, N., Wang, S., Sun, S.: One-pot synthesis of monodisperse iron oxide nanoparticles for potential biomedical applications. Pure Appl. Chem. 78, 10031014 (2006)

7. Pileni, M.P.: Fabrication and physical properties of self-organized silver nanocrystals. Pure Appl. Chem. 72, 53-65 (2000)

8. Sun, Y.P., Atorngitjawat, P., Meziani, M.J.: Preparation of silver nanoparticles via rapid expansion of water in carbon dioxide microemulsion into reductant solution. Langmuir 17, 5707-5710 (2001)

9. Henglein, A.: Reduction of $\mathrm{Ag}(\mathrm{CN})-2$ on silver and platinum colloidal nanoparticles. Langmuir 17, 2329-2333 (2001)

10. Hazarika, D., Phukan, A., Saikia, E., Chetia, B.: Phytochemical screening and synthesis of silver nanoparticles using leaf extract of Rhynchotechum ellipticum. Int. J. Pharm. Pharm. Sci. 6, 672$674(2014)$

11. Huang, J., Li, Q., Sun, D., Lu, Y., Su, Y., Yang, X., Wang, H., Wang, Y., Shao, W., He, N.: Biosynthesis of silver and gold nanoparticles by novel sundried Cinnamomum camphora leaf. Nanotechnology 18, 105104-105115 (2007)

12. Iqbal, J., Abbasi, B.A., Mahmood, T., Hameed, S., Munir, A., Kanwal, S.: Green synthesis and characterizations of Nickel oxide nanoparticles using leaf extract of Rhamnus virgata and their potential biological applications. Appl. Organomet. Chem. 33, e4950 (2019)

13. Kumar, V., Yadav, S.K.: Plant-mediated synthesis of silver and gold nanoparticles and their applications. J. Chem. Technol. Biotechnol. 84, 151-157 (2009)

14. Koukoui, O., Agbangnan, P., Boucherie, S., Yovo, M., Nusse, O., Combettes, L., Sohounhloué, D.: Phytochemical study and evaluation of cytotoxicity, antioxidant and hypolipidemic properties of Launaea taraxacifolia leaves extracts on cell lines HepG2 and PLB985. Am. J. Plant Sci. 6, 1768-1779 (2015)

15. Sakpere, A.M.A., Aremu, O.A.: The growth of Launaea taraxacifolia (Asteraceae) and its response to shading. Res. J. Bot. 3, 90-96 (2008)

16. Dansi, A., Adjatin, A., Adoukonou-Sagbadja, H., Faladé, V., Yedomonhan, H., Odou, D., Dossou, B.: Traditional leafy vegetables and their use in the Benin Republic. Genet. Resour. Crop Evol. 55, 1239-1256 (2008)

17. Dansi, A., Vodouhè, R., Azokpota, P., Yedomonhan, H., Assogba, P., Adjatin, A., Loko, L., Dossou-Aminon, I., Akpagana, K.: Diversity of the neglected and underutilized crop species of importance in Benin. Sci. World J. 2012, 932947 (2012) 
18. Krishnamoorthy, P., Jayalakshmi, T.: Preparation, characterization and synthesis of silver nanoparticles by using Phyllanthusniruri for the antimicrobial activity and cytotoxic effects. J. Chem. Pharm. Res. 4, 4783-4794 (2012)

19. Krishnan, R., Arumugam, V., Vasaviah, S.K.: The MIC and MBC of silver nanoparticles against Enterococcus faecalis-a facultative anaerobe. J. Nanomed. Nanotechnol. 6, 1000285 (2015)

20. Veerasamy, R., Xin, T.Z., Gunasagaran, S., Xiang, T.F.W., Yang, E.F.C., Jeyakumar, N., Dhanaraj, S.A.: Biosynthesis of silver nanoparticles using Mangosteen leaf extract and evaluation of their antimicrobial activities. J. Saudi Chem. Soc. 15, 113-120 (2011)

21. Obaid, A.Y., Al-Thabaiti, S.A., Al-Harbi, L.M., Khan, Z.: Extracellular bio-synthesis of silver nanoparticles. Glob. Adv. Res. J. Microbiol. 3, 119-126 (2015)

22. Ebrahiminezhad, A., Barzegar, Y., Ghasemi, Y., Berenjian, A.: Green synthesis and characterization of silver nanoparticles using Alcea rosea flower extract as a new generation of antimicrobials. Chem. Ind. Chem. Eng. Q. 23, 31-37 (2017)

23. Dhand, V., Soumya, L., Bharadwaj, S., Chakra, S., Bhatt, D., Sreedhar, B.: Green synthesis of silver nanoparticles using Coffea arabica seed extract and its antibacterial activity. Mater. Sci. Eng. C 58, 36-43 (2016)

24. Nateghi, M.R., Hajimirzababa, H.: Effect of silver nanoparticles morphologies on antimicrobial properties of cotton fabrics. J. Text. Inst. 108, 806-813 (2014)

25. Richardson, A., Chan, B.C., Crouch, R.D., Janiec, A., Chan, B.C., Crouch, R.D.: Synthesis of silver nanoparticles: an undergraduate laboratory using green approach. Chem. Educ. 11, 331-333 (2006)

26. Li, S., Qui, L., Shen, Y., Xie, A., Yu, X., Zhang, L., Zhang, Q.: Green synthesis of silver nanoparticles using Capsicum annum $\mathrm{L}$ extract. Green Chem. 9, 852-858 (2007)

27. Mirzaei, A., Janghorban, K., Hashemi, B., Bonyani, M., Leonardi, S.G., Neri, G.: Characterization and optical studies of PVPcapped silver nanoparticles. J. Nanostruct. Chem. 7, 37-46 (2017)

28. Banerjee, P., Satapathy, M., Mukhopahayay, A., Das, P.: Leaf extract mediated green synthesis of silver nanoparticles from widely available Indian plants: synthesis, characterization, antimicrobial property and toxicity analysis. Bioresour. Bioprocess. 1, 3 (2014)

29. Sarkar, S., Jana, A.D., Samanta, S.K., Mostafa, G.: Facile synthesis of silver nano particles with highly efficient anti-microbial property. Polyhedron 26, 4419-4426 (2007)

30. Zawadzka, K., Kądzioła, K., Felczak, A., Wrońska, N., Piwoński, I., Kisielewska, A., Lisowska, K.: Surface area or diameterwhich factor really determines the antibacterial activity of silver nanoparticles grown on $\mathrm{TiO}_{2}$ coatings? New J. Chem. 38, 3275-3281 (2014)

31. Robertson, J.D., Rizzello, L., Avila-Olias, M., Gaitzsch, J., Contini, C., Magoń, M.S.: Purification of nanoparticles by size and shape. Sci. Rep. 6, 27494 (2016)
32. Prabakaran, M., Subha, K., Thennarasu, V., Merinal, S.: Biosynthesis of silver nanoparticles using Sphaerulina albispiculata and evaluation of antibacterial activity. Eur J. Exp. Biol 2, 297-303 (2012)

33. Tontowi, A.E., Perkasa, D.P., Siswomihardjo, W., Darwis, D.: Effect of polyvinyl alcohol (PVA) blending and gamma irradiation on compressive strength of FHAp/Fgel composite as candidate of scaffold. Int. J. Eng. Technol. 8, 108-116 (2016)

34. Deshi, J.J., Barminas, J.T., Onwuka, J.C., Dass, P.M., Maitera, O.N., Muazu, I.: Antimicrobial efficacy of biosynthesized silver nanoparticles from different solvent extracts of Waltheria americana root. J. Anal. Sci. Technol. 7, 23 (2016)

35. Sheikholeslami, S., Mousavi, S.E., Ashitiani, H.R.A., Doust, S.R.H., Rezayat, S.M.: Antibacterial activity of silver nanoparticles and their combination with Zataria multiflora essential oil and methanol extract. Jundishapur J. Microbiol. 9, e36070 (2016)

36. Balashanmugam, P., Kalaichelvan, P.T.: Biosynthesis characterization of silver nanoparticles using Cassia roxburghii DC. aqueous extract and coated on cotton cloth for effective antibacterial activity. Int. J. Nanomed. 10, 87-89 (2015)

37. Banala, R.R., Nagati, V.B., Karnati, P.R.: Green synthesis and characterization of Carica papaya leaf extract coated silver nanoparticles through X-ray diffraction, electron microscopy and evaluation of bactericidal properties. Saudi J. Biol. Sci. 22, 637-644 (2015)

38. Carlson, C., Hussain, S.M., Schrand, A.M., Braydich-Stolle, L.K., Hess, K.L., Jones, R.L., Schlager, J.J.: Unique cellular interaction of silver nanoparticles: size-dependent generation of reactive oxygen species. J. Phys. Chem. B 112, 13608-13619 (2008)

39. Park, J., Lim, D.-H., Lim, H.-J., Kwon, T., Choi, J., Jeong, S., Choi, I.-H., Cheon, J.: Size dependent macrophage responses and toxicological effects of Ag nanoparticles. Chem. Commun. 47, 4382-4384 (2011)

40. Park, M.V.D.Z., Neigh, A.M., Vermeulen, J.P., de la Fonteyne, L.J.J., Verharen, H.W., Briedé, J.J., van Loveren, H., de Jong, W.H.: The effect of particle size on the cytotoxicity, inflammation, developmental toxicity and genotoxicity of silver nanoparticles. Biomaterials 32, 9810-9817 (2011)

41. Prabhu, S., Poulose, E.K.: Silver nanoparticles: mechanism of antimicrobial action, synthesis, medical applications, and toxicity effects. Int. Nano Lett. 2, 32 (2012)

42. Sondi, I., Salopek-Sondi, B.: Silver nanoparticles as antimicrobial agent: a case study on E. coli as a model for Gram-negative bacteria. J. Colloid Interface Sci. 27, 177-182 (2004)

Publisher's Note Springer Nature remains neutral with regard to jurisdictional claims in published maps and institutional affiliations. 